\title{
Artroplastide kemik çimentosunun geçmişi ve geleceği
}

\author{
Bone cement in arthroplasty -past and future
}

\author{
Faik Altıntaş, Onur Kocadal \\ Yeditepe Üniversitesi Hastanesi Ortopedi ve Travmatoloji Anabilim Dalı, İstanbul
}

\begin{abstract}
Artroplasti cerrahisi, günümüzde sonuçları itibariyle ortopedi ve travmatolojinin en yüz güldürücü tedavi yöntemlerinden birisidir. Yaklaşık altmış yıl önce Sir John Charney'in kalça artroplastisinde akrilik kemik çimentosu kullanmaya başlaması ile, artroplasti cerrahisinin "altın dönemi"nin başladığı söylenebilir. O günden bu yana, materyal teknolojisindeki ve çimento uygulama tekniklerindeki gelişmelere paralel olarak artroplasti cerrahisi dramatik şekilde gelişmiştir. Çimentolu protez uygulamalarında başarılı sonuçlara ulaşılabilmesi ve tekniğin geliştirilebilmesi için, çimentonun tarihsel gelişimi, kimyasal bileşenleri, uygulama teknikleri ve viskozite gibi kavramların anlaşılması gerekmektedir.
\end{abstract}

Anahtar sözcükler: kemik çimentosu; artroplasti
Arthroplasty is one of the most satisfying sub-specialties of orthopedics and traumatology. It can be said that the 'golden period' of arthroplasty started after Sir John Charney started using acrylic bone cement in total hip arthroplasty about six decades ago. Since that time, joint reconstruction surgery has developed dramatically in parallel with the developments in material technology and cement application techniques. In order to achieve successful results and technical advancements in cemented joint reconstruction surgery, it is necessary to understand concepts such as historical development of cement, chemical components, application techniques, and viscosity.

Key words: bone cement; arthroplasty
P

rotez cerrahisi, ortopedi ve travmatoloji alanında son 50 yılda çarpıcı şekilde gelişme göstermiştir. Hastaların yaşam kalitesini ciddi şekilde arttıran protez cerrahisinin gelişimi; metalurji, triboloji, biyo-teknoloji ve materyal bilimlerindeki gelişmelere paralel seyretmiştir. Akrilik yapıdaki kemik çimentosunun kullanımı, protez cerrahisinin dönüm noktalarından birisidir. Protez cerrahisi, başarılı çimentolama tekniği sayesinde 'uzun süreli sağkalım' hedefine oldukça yaklaşmıştır.

\section{KEMIK ÇIMENTOSUNUN TARIHI}

'Çimento' kavramı ortopedi ve travmatoloji tarihinde ilk olarak Alman bilim adamı Themistokles Gluck tarafından kullanılmıştır. Gluck, fildişinden imal ettiği diz protezini kemiğe daha iyi tespit edebilmek için alçı, bakır amalgam ve toz macun karışımını kullanmıştır. ${ }^{[1]}$ Günümüzde kemik çimentosu için kullanılan materyal polimetilmetakrilat (PMMA)'dır. Otto Röhm, metilmetakrilatın kimyasal ve fiziksel özelliklerini ilk tanımlayan araştırmacıdır. ${ }^{[2]}$ Röhm'ün 1901 yılında "Akrilik Asitin Polimerizasyon Ürünleri" isimli tezi sonrası metilmetakrilat, endüstride cam benzeri sert madde anlamına gelen 'plexiglass' adı ile denizaltı periskoplarında, silah taretlerinde ve havacılık sanayisinde yoğun olarak kullanılmıştır. [1] PMMA'nın klinik olarak ilk kullanımı, 1938 yılında maymunlarda kraniyal defektlerin kapatılması amacıyla gerçekleşmiştir.[3] 1940 yılında Schnebel, metilmetakrilat'ın polimerizasyon prensiplerini tanımlamıştır. 1941'te insanlarda, PMMA kullanılarak kraniyal defektlerin onarılmasına başlanmıştır. ${ }^{[4]} 1943$ yılında Kulzer ve Degussa metilmetakrilatın oda ısısında tersiyel aromatik aminler yardımı ile polimerizasyonunu ortaya koymuşlardır. ${ }^{[5]}$

PMMA, keşfinin erken dönemlerinde toz polimer ve likit monomerik kısımlarının $100^{\circ} \mathrm{C}$ 'ye kadar ısıtılarak reaksiyona girmesi ile elde ediliyordu. İlerleyen dönemlerde, polimer ve monomerlerin reaksiyona girmesi için aktivatör kullanımı sayesinde, PMMA'nın oda

- İletişim adresi: Prof. Dr. Faik Altıntaş, İçerenköy Mah. Hastane Sok. No: 4, 4/1 Ataşehir, İstanbul Tel: 0532 - 2319984 e-posta: faltintas@superonline.com

- Geliș tarihi: 24 Ocak $2019 \quad$ Kabul tarihi: 24 Ocak 2019 
ısısında elde edilmesi sağlandı. Bu sayede klinik kullanımı yoğunluk kazandı. ${ }^{[4]}$ Akrilik, 1950 yılında Judet tarafindan kalça protezinde femoral komponentin başında kullanılan materyal olarak denenmiş, ancak başarısız olmuştur. ${ }^{[6]} 20$. yüzyılın ortalarına gelindiğinde PMMA, biyo-uyumluluğu, dayanıklı bir materyal olması ve transparan oluşu gibi avantajları nedeniyle diş hekimliği alanında yoğun şekilde kullanılmaya başlandı. ${ }^{[4]} 1953$ yılında Haboush, akrilik materyalinin kemik ve protez arasında boşluk doldurucu olarak kullanılabileceği fikrini öne sürmüştür. ${ }^{[7]} 1957$ yılında Wiltse ve ark., akrilik kemik çimentosunun ortopedik cerrahi alanında kullanılabilecek bir materyal olduğunu belirterek çimentonun potansiyel yararlarını deneysel olarak ortaya koymuşlardır. ${ }^{[8]} 1958$ yılında Sir John Charnley, paslanmaz çelik femoral stem ve yüksek yoğunluklu polietilen asetabular komponentleri ilk kez çimento ile uygulamış, akabinde 1960'ta erken dönem sonuçlarını yayımlamıştır. ${ }^{[9]}$ Çimentolu uygulamalar sonrası sekiz yıllık takiplerde sadece $\% 2$ oranında başarısızlık rapor edilmiştir. ${ }^{[10]}$ Avrupa'da protez cerrahisinde kullanımından yaklaşık 10 yıl sonra 1970'lerde Amerikan Besin ve İlaç Dairesi (FDA), PMMA'nın diz ve kalça protezlerinde kullanımına onay vermiştir. ${ }^{[5]}$

\section{KEMIK ÇIMENTOSUNUN BILEŞENLERI VE KIMYASI}

Modern PMMA'nın içeriği ve geliş̧imi klinik ihtiyaçlar doğrultusunda şekillenmiştir. PMMA, ilk başta toz olan polimer ve sıvı monomerin, yüksek ısıda karıştırılması ile elde ediliyordu. Toz ve sıvı bileşenlerin ekzotermik reaksiyonu sonrası, monomerlerin polimerik yapıya eklenmesiyle, akrilik sement yapısı meydana gelmektedir. Bununla beraber, bu toz ve sıvı bileşenlerin içine bir takım farklı kimyasallar da katılarak ideal çimentonun elde edilmesi amaçlanmıştır. Bunun yanı sıra, akrilik çimentonun klinik kullanıma girebilmesi için reaksiyonun oda ısısında gerçekleşmesi gerekiyordu. Sıvı bölüme eklenen dimetil-paratoludin ve toz kısma eklenen dizbenzoil peroksid ile, polimerizasyonun oda ısısında gerçekleştirilmesi sağlandı. Bir de, erken polimerizasyonun önlenmesi için sıvı yapı içerisine hidrokinon eklenerek polimerizasyonun optimal koşullarda gerçekleştirilmesi sağland.. ${ }^{[2]}$ Radyografinin rutin ortopedik değerlendirmede kullanıma girmesi neticesinde, çimentonun radyoopasitesinin sağlanması için sıvı kısma baryum sülfat ve zirkonyum dioksit gibi maddeler eklendi. ilerleyen dönemlerde, artroplasti cerrahisinde özellikli riskli olgularda, çimentonun içine antibiyotik eklenmesi fikri popülarite kazandı. Bu amaçla, toz kısma gentamisin, tobramisin, sefuroksim, kolistin, vankomisin gibi antibiyotikler eklenmiştir. ${ }^{[3,5]}$
Çimento içeriğine eklenen antibiyotikler ve diğer bileşenler çimentonun katılaşma süresini etkilemektedir. Ortam sıcaklığı, nem ve karıştırma hızı, katılaşma süresini etkileyen diğer parametrelerdir. Bu faktörler, etkilerini çimentonun viskozitesini değiştirerek gösterir.

\section{VISKOZITE}

Çimentonun viskozitesi yani akışkanlığı, çimentonun içeriği ile ilişkilidir. Polimer oranı arttıkça çimentonun viskozitesi artmakta, monomer oranı arttıkça viskozite azalmaktadır. Tipik olarak çimento reaksiyonu dört fazdan meydana gelir. ${ }^{[3]}$ Bu fazlar; karıştırma, bekleme ve çalışma sürelerini etkilemektedir.

Çimentonun viskozitesi bekleme ve katılaşma sürelerini etkilemektedir. Viskozite arttıkça, bekleme süresi kısalmakta, katılaşma süresi artmaktadır. ${ }^{[11]}$ Ortam ISISı ve nem viskoziteyi direkt olarak etkileyen faktörlerdir. Düşük sıcaklık ve yüksek nem çimentonun hazırlanış süresini uzatmaktadır. ${ }^{[12]}$ Çimento viskozitesini etkileyen bir diğer konu da sterilizasyon tekniği ve buna bağlı değişen çimentonun molekül ağırlığıdır. Beta ve gama ışınları ile yapılan sterilizasyon sonrasında, çimentonun molekül ağırlığı azalmakta ve mekanik özellikleri zayıflamaktadır. ${ }^{[3]}$ Etilen oksit ile gerçekleştirilen sterilizasyon, daha karmaşık ve pahalı olmasına rağmen, çimentonun mekanik özelliklerini değiştirmemektedir. Yüksek viskoziteli çimentolama tekniğinde tespit sonuçlarının, düşük viskoziteli tekniğe kıyasla daha başarılı olduğu kabul edilmektedir. ${ }^{[5]}$ Çimentonun mekanik özelliklerini belirleyen önemli bir parametre de havadır. Çimentonun polimerizasyonunu etkileyen havanın, yapısal olarak zayıflamaya neden olduğu ortaya konmuştur. ${ }^{[2]}$ Bu nedenle, erken dönemlerde elle yapılan karıştırma işlemi yerini vakumlu karıştırıcı sistemlerine bırakmıştır.

\section{TOTAL KALÇA ARTROPLASTISINDE ÇIMENTOLOMA TEKNIKLERI}

Kemik çimentosunun hazırlanması ve uygulanması, artroplastinin başarısını en az malzemenin veya eklemleşmenin tipi kadar etkilemektedir. Klasik olarak çimentolama teknikleri üç kuşak olarak sınıflandırılabilir. Çimentonun optimal şekilde kullanılabilmesi için, tabanca kullanımı, vakum sistemi, basınçlı uygulama, basınçlı yıkama, fırça kullanımı ve tıkaç kullanımı gibi teknikler geliştirilmiştir. Günümüzde üçüncü dönem çimentolama tekniğinin modifiye edilmesi ardından dördüncü kuşak çimentolama tekniğinden bahsedilmektedir. ${ }^{[1]}$ Sınıflama temel olarak, kemik yatağının hazırlanması, çimentonun hazırlanması ve çimentonun uygulanması arasındaki değişiklikleri göz önüne sermektedir. 


\section{Birinci Kuşak Çimentolama Tekniği}

Birinci kuşak çimentolama tekniğinde, çimentonun oturacağı kemik yüzeye özel bir hazırık yapılmıyordu. Bu teknikte; el ile karıştırılan çimento, kemik yüzeyin yıkanmasını takiben, femur medullası içine antegrad olarak el yardımı ile konulduktan sonra protez çimentonun içine yerleştiriliyordu.

\section{İkinci Kuşak Çimentolama Tekniği}

Birinci kuşak çimentolama tekniği, çimentonun kemik protez ara yüzeyinde uygun dağılım göstermemesi ve gevşemeye yol açması nedeniyle yerini ikinci kuşak çimentolama tekniğine bırakmıştır. İkinci kuşak çimento tekniği, çimentonun kemik protez ara yüzeyine daha dengeli dağılması prensibine dayanarak geliştirildi. İkinci kuşak çimentolama tekniği adım adım; kalça protezinde femoral kanaldaki kansellöz kemiğin yeterli oyulması, femoral kanalın şırınga yardımı ile yıkanması, femoral kanala distal tıkaç yerleştirilmesi ve çimentonun tabanca yardımıyla retrograd yerleştirilmesi olarak tanımlanabilir.

\section{Üçüncü Kuşak Çimentolama Tekniği}

Üçüncü kuşak çimentolama tekniğinde, çimento karıştırma esnasında oluşan hava kabarcıklarının vakum yardımı ile azaltılması ve bu sayede poroziteyi indirgemek amaçlanmıştır. Bu teknikte, femoral kanal pulsatil lavaj ile yıkanır. Medulla distaline, femoral komponentten ortalama $2 \mathrm{~cm}$ kadar uzun ve medulla genişliğine uygun olacak şekilde tıkaç yerleştirilir. Retrograd teknikle, çimento tabancasıyla kemik çimentosu basınçlı olarak medullanın içine konur. Femoral komponent distal ortalayıcı ile medullanın tam ortasına yerleştirilir. ${ }^{[5]}$

\section{Dördüncü Kuşak Çimentolama Tekniği}

Klasik kitaplara girmemiş olmakla birlikte bazı yayınlarda tanımlanmış olan dördüncü kuşak çimentolama tekniği ise; üçüncü kuşak çimentolama tekniğine ek olarak proksimal ortalayıcı yerleştirilmesi olarak ifade edilmektedir. ${ }^{[1]}$

Kemik yüzeyin hazırlanması, en az çimentonun hazırlanma tekniği kadar önem taşımaktadır. Günümüzde kemik yüzeylerin çimento yerleştirmeden önce basınçlı olarak yıkanması, kan, kemik ve yumuşak doku debrisinin uzaklaştırılması ve medullanın kurulanması önemlidir.

\section{MODIFIKASYONLAR}

Çimentonun artroplastide yaygın olarak kullanılması ile birlikte, çimento içeriğinin temel bileşenlerine ek bazı materyaller eklenerek protez cerrahisinin temel sorunlarına çözüm alternatifleri üretilmeye çalışılmıştır. Artroplastinin giderek yaygınlaşmasına paralel olarak, enfeksiyon ve gevşeme gibi komplikasyonlarla karşılaşılan hasta sayısı da artmıştır. 1970'lerde Almanya Endoklinik'ten Bucholz ve ark.'nın, ciddi bir komplikasyon olan enfeksiyon riskinin azaltılması çaIışmaları ve ilerleyen yıllarda enfekte olguların tedavisinde çimento içeriğine antibiyotik eklenmesi, yapısal modifikasyonların en net örneği olarak kabul edilebilir. ${ }^{[13]}$ Enfeksiyon riskinin azaltılması için, çimentonun içerisinde antibiyotiklerden başka gümüş içeren nanopartiküller ve bakteri kaynaklı doğal antimikrobiyal yapıdaki bakteriosinler de kullanılmaktadır. ${ }^{[5]}$ Çimentonun içerisine eklenen Vitamin E ise serbest radikalleri toplayarak çimento yapısının stabilize edilmesinde katkı yapan bir diğer maddedir. ${ }^{[5]}$

\section{ÇiMENTONUN GELECEĞi}

Çimento kullanımı geçtiğimiz yüzyılın ortalarında artroplasti cerrahisinde bir dönüm noktası olmuş, gerek kimyasal içeriğindeki modifikasyonlarla gerekse uygulama tekniğindeki gelişmelerle, daha optimal hale getirilmeye çalışılmıştır. Bununla beraber, çimentolu protez uygulamaları sonrası gevşeme, cerrahi sonrası önemli bir problem olarak yerini korumaktadır. Nanoteknoloji ve materyal bilimindeki gelişmeler sayesinde, çimento teknolojisi gelişimine devam edecek gibi görünmektedir. Çimentonun biyomekanik özelliklerinin kemik dokudan farklı olması, protez ve çimento üzerinden yük dağılımının fizyolojiye aykııı olarak gerçekleşmesine ve dolayısı ile gevşemeye neden olmaktadır. Çimento örtüsü ve protez materyallerinin biyomekanik özelliklerinin kemik dokuya yaklaştırılması ile bu sorunların önüne geçilebilir.

Çimento alanında gelecek vadeden bir diğer konu da, kalsiyum fosfat gibi biyo-aktif kemik çimentolarıdır. Biyo-aktif kemik çimentoları yük taşımayan alanlardaki kemik defektlerinde kullanılan materyallerden olup, günümüzde henüz artroplasti alanında kullanılmamaktadır. Buna karşın mukavemet güçleri arttırıldığında, biyo-aktif çimentoların artroplasti alanında da kullanılmaya başlayacağı, bunun da implant sağkalım sürelerini uzatacağı öngörülebilir.

Çimentonun gelişim basamakları ve kat ettiği yol göz önünde bulundurulduğunda, gelişimleri mevcut ihtiyaçların şekillendirdiği açıkça görülmektedir. Gelinen son noktada, en ciddi problemin gevşeme olduğu söylenebilir. Literatürde gevşemeye yönelik temel ve klinik bilgi dağarcığındaki gelişmeler sayesinde, bu sorunun çözümüne odaklanıldığını, çimentolama tekniğinin hala gelişime açık olduğu ifade edilebilir. 


\section{KAYNAKLAR}

1. Maggs J, Wilson M. The Relative Merits of Cemented and Uncemented Prostheses in Total Hip Arthroplasty. Indian J Orthop 2017;51(4):377-85. Crossref

2. Jaeblon T. Polymethylmethacrylate: properties and contemporary uses in orthopaedics. J Am Acad Orthop Surg 2010;18(5):297-305. Crossref

3. Kühn K-D. Properties of Bone Cement: What is Bone Cement? In: Breusch S, Malchau H, editors. The Well-Cemented Total Hip Arthroplasty: Theory and Practice. Germany: Springer Science \& Business Media; 2005. pp.52-9.

4. Nottrott M. Acrylic bone cements: influence of time and environment on physical properties. Acta Orthop Suppl 2010;81(sup341):1-27. Crossref

5. Vaishya R, Chauhan M, Vaish A. Bone cement. J Clin Orthop Trauma 2013;4(4):157-63. Crossref

6. Judet J, Judet R. The use of an artificial femoral head for arthroplasty of the hip joint. J Bone Joint Surg Br 1950;32$\mathrm{B}(2): 166-73$. Crossref

7. Haboush EJ. A new operation for arthroplasty of the hip based on biomechanics, photoelasticity, fast-setting dental acrylic, and other considerations. Bull Hosp Joint Dis 1953;14:242-77.
8. Wiltse LL, Hall RH, Stenehjem JC. Experimental studies regarding the possible use of self-curing acrylic in orthopaedic surgery. J Bone Joint Surg Am 1957;39$A(4): 961-72$. Crossref

9. Charnley J. Anchorage of the femoral head prosthesis to the shaft of the femur. J Bone Joint Surg Br 1960;42-B(1):28-30. Crossref

10. Griffith MJ, Seidenstein MK, Williams D, Charnley J. Eight year results of Charnley arthroplasties of the hip with special reference to the behavior of cement. Clin Orthop Relat Res 1978;(137):24-36. Crossref

11. Webb JC, Spencer RF. The role of polymethylmethacrylate bone cement in modern orthopaedic surgery. J Bone Joint Surg Br 2007;89-B(7):851-7. Crossref

12. Marangoz S. Kemik çimentosu. TOTBID Dergisi 2011;10:103-8.

13. Buchholz HW, Elson RA, Engelbrecht E, Lodenkamper $H$, Rottger J, Siegel A. Management of deep infection of total hip replacement. J Bone Joint Surg Br 1981;63-B(3):342-53. Crossref 